\title{
Virtual Reality as a Vehicle for Reimagining Creative Literacies, Research and Pedagogical Space
}

\author{
Tashya Orasi \\ Lakehead University \\ Pauline Sameshima \\ Lakehead University
}

In recent years, virtual reality technologies have become increasingly accessible; and in educational contexts, this technology has the potential to expand the literacy of creativity and provide re-orientations for pedagogical thinking and meaning making. Using the Parallaxic Praxis methodology (Sameshima et al., 2019) to generate data understandings in a research project exploring teacher creativity, artistresearchers used Google Tilt Brush to investigate: How do entanglements of language, literacy and VR alter the pedagogical space of creativity? How is creativity enabled in VR? And, what does this dynamic pedagogical space offer to educators? Pedagogical sites of learning from the virtual renderings generated new perspectives to examine the intersections of creative agency, literacy and expression, learning spaces and research design - all of which are increasingly important as educational practises evolve in the wake of the COVID-19 pandemic.

Keywords: creative literacy, pedagogical space, virtual reality, multiliteracies, parallaxic praxis

\section{ORIENTING}

Phrases like the "poverty of imagination" are used to critique the current state of education and explain the wide-sweeping absence of creative capacity in contemporary society, but they also allude to its absolute necessity as part of a broader societal fabric and functioning (Eisner, 2002; Larson et al., 2020; Robinson, 2017; UNESCO, n.d.). Hayes et al. (2015) posit that "the imagination is an ethnographic strategy and method ... offering the possibility of a more abundant, just, and connected planet, . . a space constituted by the creative, generative, and imaginative capacities of human social experience (Brah, 2002)" (p. 37). Drawing from Imagination as Method (Hayes et al., 2015), we adopt the notion of the global socius, and affirm "the social space of the global acquires characteristics that are very different from . . the territorialized, contained, and bounded nation-state model" (p. 37). Here, the description of the global is a "particular kind of space/time matrix". The global socius is a way to conceptualize "a virtual poiesis that generates an imaginative and creative geography of being and action that both exceeds and intertwines the stuff of direct human experience" (p. 14). We extend the global socius construct into the virtual reality (VR) space, merging imagination as thinking and creativity as material making. "We follow Cornelius Castoriadis (2002) in suggesting that imagination is the energy through which consciousness and the material world are integrated and society is generated" (p. 37). 
The emergence of mainstream virtual reality technologies and the increasing computing capacity of smartphones and mobile technology has made three-dimensional tools an exploratory site for the development of creative literacies. There are numerous and often interchangeable definitions for information literacy, digital literacy and creative literacy; however, foundationally, literacies point to empowering attitudes and access to skills, tools and options which allow the learner to make meaning of various texts (inclusive of non-textual texts). Literacies enable a pathway of understanding between conception, meaning-making, and creation. Ginsberg (2012) describes creativity literacy as "knowledge that gives individuals the power to transform their ideas into reality" (p. 92). Thinking across literacy domains, virtual reality (VR) enables such a reimagining of the creative learning space while expanding the language of creativity to a medium with significant pedagogical implications.

In addition to reconciling the isolating and distancing of learning spaces left behind in the wake of the COVID-19 pandemic, VR can be a lens to critically examine the threshold spaces for, and the complexity of, creative literacy in education. All educational spaces communicate messages about how learning is expected (Eisner, 2017) and are delineated by boundaries of time, space and power structures. Hitchcock and Hughes (1989) assert that "how human beings orientate towards and structure the visible and invisible boundaries we refer to as space, environments [and] territories" can "reveal important, and often invisible aspects of our culture" (p. 171). The authors consider how VR may be considered as an important sociopetal space (Osmond, 1959 as cited in Hitchcock \& Hughes, 1989) which encourages cooperation, social interaction, closeness, and pedagogical communication.

In this paper, the authors reflect on their experience of using the Parallaxic Praxis methodology (Sameshima et al., 2019) to generate deeper understandings of their personal identities as teachers and creatives through Google Tilt Brush software using the Oculus Quest VR system. Drawing from reflexive practice of past research (Sameshima et al., 2018b; 2019c; Sameshima, 2020) and experiences, three teacher-researchers met regularly over the course of a year to discuss and play with thinkings on teacher creativity. To guide their reflection, the authors asked: How do entanglements of language, literacy and virtual reality alter the pedagogical space of creativity? How can creativity orientations change in virtual reality, and what does this dynamic pedagogical space offer to educators' literacies? Engaging with the possibilities of this software provided the artist-researchers the opportunity to both imagine and inhabit the space where new understandings of data were generated. Expanding the literacy of creativity across disciplines and into virtual realms, the modality of their virtual paintings represent new ways of thinking, being and entering research.

A case for this study's importance can also be made by the ramifications of a rapid transition to digital learning spaces during the COVID-19 pandemic. The necessary movement to online education has drawn criticism for increasing student disengagement and widening equity gaps (Gillis \& Krull, 2020). The illumination of these disparities has fostered an environment of educational critique that makes a different vision for education and pedagogical spaces possible. As a radical proposition to supplement educational spaces, virtual reality provides an opportunity for redesigned online pedagogies to increase access, equity, student engagement, and learning, while fostering meaningful interactions between teachers and students. While investigating the phenomenon of creativity through the digital VR space led to important situated realizations as teachers, researchers and learners; more significantly, in this research-creation (Loveless, 2019) process, the researchers discovered VR to be a revolutionary tool for pedagogical communication, the enhancement of creative literacy, and the enrichment of research data analysis.

\section{PEDAGOGY IN VIRTUAL REALITY}

Virtual reality as an important pedagogical tool first appeared in the literature in the mid 1990s. Psotka (1995) wrote extensively on the psychological benefits of immersive VR, VR as a mode of communication between "symbolic form and mental representation, and between collaborators in conceptual worlds" (p. 410), and VR as a learning tool to potentially enhance conceptual understanding of subject matter as well as knowledge transfer between teacher and student. Although much of VR's early literature focused on the applications of VR for enhancing command functions of large-scale spatial navigation and console 
simulations typical of military training (Jense \& Kuijper, 1993; Sebrechts, Psotka \& Knott, 1994;) as well as science, psychics and space explorations (Magee, 1993), Psotka (1994) and others argued that VR showed great potential in broader educational contexts to enhance understanding, address education equity issues for students separated from access to schools while living in remote areas, as well as provide opportunities for engagement and communication to students with limited physical mobility. Others further speculated on the potential of VR to create networks of "educational habitats" (Loeffler, 1993; Hughes \& Moshell, 1997) that would promote social interaction and collaborations globally, foster the exploration of places and things that would be otherwise inaccessible (Pantelidis, 1993) and enhance student imagination through this form of edutainment. Much of the literature from this decade called for the imminent preparedness of teachers for the practical applications of VR in the classroom (Pantelidis, 1993).

In the decades following this pioneering work, the advent of mobile learning and wide-scale accessibility of mobile devices dramatically increased, in addition to the availability of online courses and asynchronous learning. Researchers in technology-enhanced learning, Traxler and Wishart (2011), had envisioned that learning with mobile devices would greatly enhance student-centered and authentic learning; however, as Cochrane (2016) points out, current deployment of mobile learning has failed to meet these aims and often results in the replication of course content from institutional learning management systems (i.e., Desire to Learn, BlackBoard) onto personal cell phones or tablets. Up until 2016, further complicating the advancement of VR in education was the fact that the majority of literature available, as well as VR software and hardware, was held proprietarily, making it cost-prohibitive for researchers to advance this area of study independently despite prior speculations of its classroom applications (JohnsonGlenberg, 2018). In 2016 however, Cochrane (2016) suggested that as high-end headsets became more commercially available later that year, VR growth would be exponential in the coming decade as a $\$ 100$ billion industry, and that implications for use of personal devices for VR and augmented reality (AR), through disciplines such as paramedicine, journalism and new media, among others, would soon begin to bridge this gap.

Since then, VR has gained significant traction in the 3D virtual gaming industry, with 2019 marking an important year for commercially accessible VR headsets such as Oculus Quest. No longer requiring expensive gaming computers and sophisticated setups, the Oculus products are offered to global consumer markets at a price point similar to other mainstream gaming consoles (Gronstedtgroup, 2020) and with dramatically improved graphics, comfort and user-friendly interfaces (Varjo, 2021). Private industry has been rapidly adopting VR for collaborative product design, sales exhibitions, behavioural research, data visualization and training simulations among other applications. Compound growth in virtual reality is expected between 35-52\% annually from 2020 to 2024 (Varjo, 2021), which will meet, if not exceed, earlier industry predictions especially in light of increasing competitive pressures as industry continues to respond to the pandemic. VR's advancement and promotion in high profile Canadian and international media arts initiatives have also included the production of VR storytelling, games, curriculum and other immersive content for Canada's 150th celebration (Sesqui, 2017-2021), independent films in CBCVR, and more. In 2020, the Canada Council for the Arts announced funding for the UK-Canada Immersive Exchange StoryFutures Academy for immersive storytelling and filmmaking (Canada Council for the Arts, 2020).

Notwithstanding these innovative virtual reality projects, virtual reality in the Canadian educational landscape is still very much in its infancy. While the benefits of virtual reality were introduced by Lenovo (Technology Company) to the Canadian higher education sector in 2018 , (Li, 2018), at the postsecondary level in Ontario and British Columbia, the use of virtual reality in the classroom in 2020 was limited to select pilot programs and predominantly focused on its use for simulations and consumptive content in skilled trades such as engineering, instrumentation, mapping, surgery, rehabilitation, medicine, molecular science, business modelling, health care and the like (Lewington, 2020). External training simulations (manipulation of objects and controls) have extended to internal body training interventions. For example, in 2020, Psious launched a psychotherapy VR unit and program to support patients' mental health through immersive environments. Using VR environment exposure, patients learn interventions such as muscle relaxation, mindfulness techniques and other systematic desensitization techniques. As a new field, there is still much speculation about how the widespread adoption of VR will change the face of teaching and 
learning in the near future (Babich, 2019; Bengfort, 2020; Lee, 2021) and faculties of education, including Lakehead University and OISE at the University of Toronto, have responded by designing courses and resources to prepare teachers for the implementation of virtual reality technologies in Canadian classrooms (https://guides.library.utoronto.ca). Thompson et al. (2020) report higher student perceived engagement with VR than other pedagogical methods in an undergrad nursing education course. Further research is needed on how and in what ways VR contributes to and changes the pedagogical space in professional practice; and most significantly, what are the transformative ways VR can be used as a tool to develop and grow creative literacy?

\section{PERSPECTIVES \& RESEARCH DESIGN}

Literacy is a way of knowing and reading the world (Cole \& Masny, 2009). Multiple literacies theory considers literacy beyond the confines of "school based literacies" to include the concept of literacies as an evolving social construct that takes on "multiple meanings conveyed through words, gestures, attitudes, ways of speaking, writing, [and] valuing" that "are taken up as visual, oral written and tactile" (Masny, 2009 , p. 14). Our multimodal research project considers creativity a literacy by exploring connections between creativity, literacy, language, and pedagogical practice. Further, following Masny's (2009) view that "literacies constitute ways of becoming" (p. 14), literacy is a process achieved through continuous investments of effort, event and experience. The artist-researchers employ this theoretical perspective to consider a theory of creative literacy, its actualization in the virtual reality space and the potential for educational researchers to examine the intersections of creative literacy, empathy in the pedagogical space and advancement of arts integrated research methodologies.

This post-qualitative arts integrated inquiry also employs the curricular concept of $m a$ to build knowledge of teaching and learning through an aesthetic, embodied, multilayered experience that "allows for possibilities not yet imagined" (Sameshima, 2019, p. 8). The Japanese concept of ma has been used by curriculum theorists to describe what is expressed, repressed, or suppressed in a space between two markers (Hasebe-Ludt, 2019; James, 2019; Leggo, 2019). It is a gateway into the in-between that other scholars have described as prosody, liminality, third space and other terms. Like the virtual reality canvas itself, $m a$ is the pregnant void (Sameshima et al., 2019b). The authors consider how a conceptual framework shaped by new materiality and curricular theories merge to hold space for creative engagement.

As an interdisciplinary research methodology, Parallaxic Praxis (Sameshima et al., 2019) employs "multi-perspective analysis, multi-modal investigations, informal and directed dialogic conversations, innovative knowledge creation, and models of residual and reparative research" (p. 1). In this model, as seen in Figure 1, multiple perspectives (including varied responses to data) are invited to sit in juxtaposition in order to generate new understandings, provoke dialogue and make meaning. 
FIGURE 1

PARALLAXIC PRAXIS RESEARCH MODEL

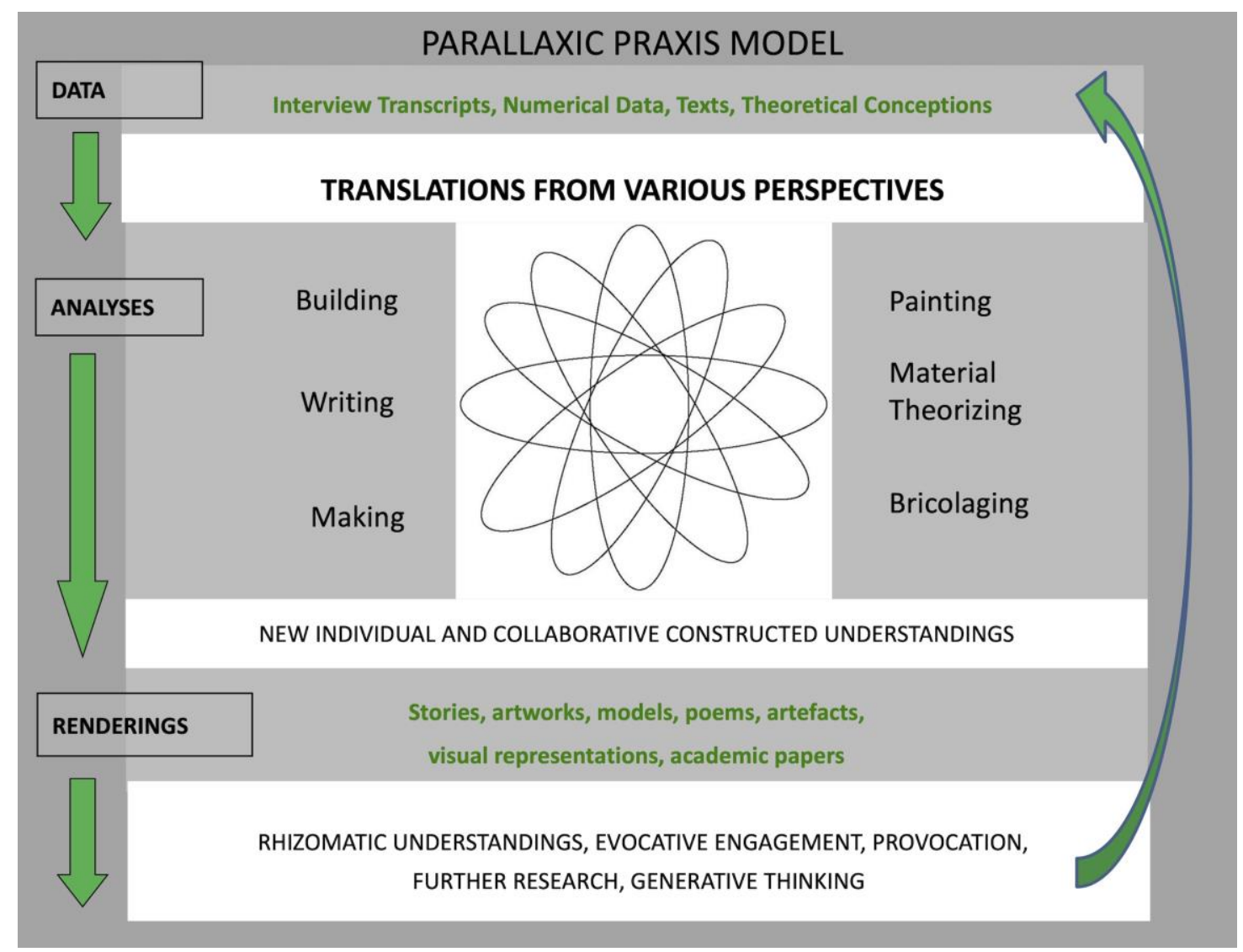

Image reproduced with permission from Parallaxic Praxis (Sameshima et al., 2019, p. 260)

Merging multiliteracies theory (Cole \& Masny, 2009), imagination as method (Hayes et al., 2014) and new materiality constructs (Barad, 2007), this research model is uniquely suited to a field of inquiry into VR as a pedagogical space and vehicle for creative language. These theoretical alignments and virtual reality itself, openly challenge longstanding ontological and epistemological stabilities in educational thought in exciting and important ways.

The Parallaxic Praxis model is cyclical, whereby renderings (translations of data into another modality) are discussed and analyzed and then another research cycle can occur. The Catechization Process ${ }^{1}$ occurs after renderings are produced and is a systematic activity used to analyze the renderings and provoke new thinking about the data (Sameshima et al., 2019). The artist-researchers in this project drew from transcript data from a previous catechization cycle (part of a larger funded project on teacher creativity ${ }^{2}$ ), current literature, and personal experiences in their specific fields of educational study to explore creativity processes.

\section{SPACIAL ENTRANCES: LEARNINGS FROM VR MAKING}

The art-making we created in VR is process-art, an arts-informed research process (Cole \& Knowles, 2001) where the art-making process is specifically used to generate conversation. We did not pre-plan what we each contributed and took turns building on one another's work. While one person wore the VR headset, the other two were able to view the cast screen (a projection of the user's view). Throughout the makings, we conversed about our experiences as artists, teachers, and researchers. 
The artwork can be seen as four constructions. The video opens with a skeletal ribcage emitting light yet the body of the teacher is absent and suspended in a bleak and desolate environment. We were lamenting the hope and desire of teachers and reflecting on teacher selfhood and agency. The body of the video is made up of a binary construction--a tree in bloom overlooking a desk, surrounded in a garden space with life, intricate growth, entwined support and a grounded sense-of-place; and within the same garden space but in opposition, sharp-edged, leaning infrastructures appear precarious but present. Ribbons of celebration decorate both sides of the garden. The video compilation is a hopeful piece, one that attempts to capture possibility, the life giving force and celebrations and joy from community that embody a specific educational experience - "one where the learner has initiated a physical gesture or movement that is well mapped to the content to be learned" (Johnson-Glenberg, 2018, p. 1). In the final section of the video, a lone figure made of stardust stands in space holding a poster exclaiming "paintings for sale." This section reflects the sometimes lonely otherness of embracing artistic identities and the fleeting and contradictory aspirations for the social value of creativity.

As VR lends itself well to the integration, connection and expression of prior experiences, the imported image of the white desk is part of a previous 3D printed diorama, "Raising Acuity" (Orasi \& Sameshima, 2020), in which creativity and the foundations of education and curriculum were explored from a leadership and policy perspective through $3 \mathrm{D}$ printing. In this project, the desk was the starting point and is a metaphor for Eisner's notion of "opacity" (2017, p. 31), which contends that artistic inquiry into qualitative research brings forward habituated meanings and stimulates important conversation.

The collaborative rendering process culminated in the video Spacial Entrances (Figure 2). Thematic areas that arose in the discussions pointed to curiosities and tensions about efficiency and creativity in education; the redirecting of life trajectories and selfhood; playing, tinkering and ephemerality; the growing of creative agency; celebrations of leaving in education; and the social value of creative literacy in education. From these discussions, the authors further examined sites of learning, specifically: 1) boundaries and groundings; 2) creative literacy and expression; and 3) gaze in pedagogy.

\section{FIGURE 2 \\ SCREENSHOT OF SPACIAL ENTRANCES}

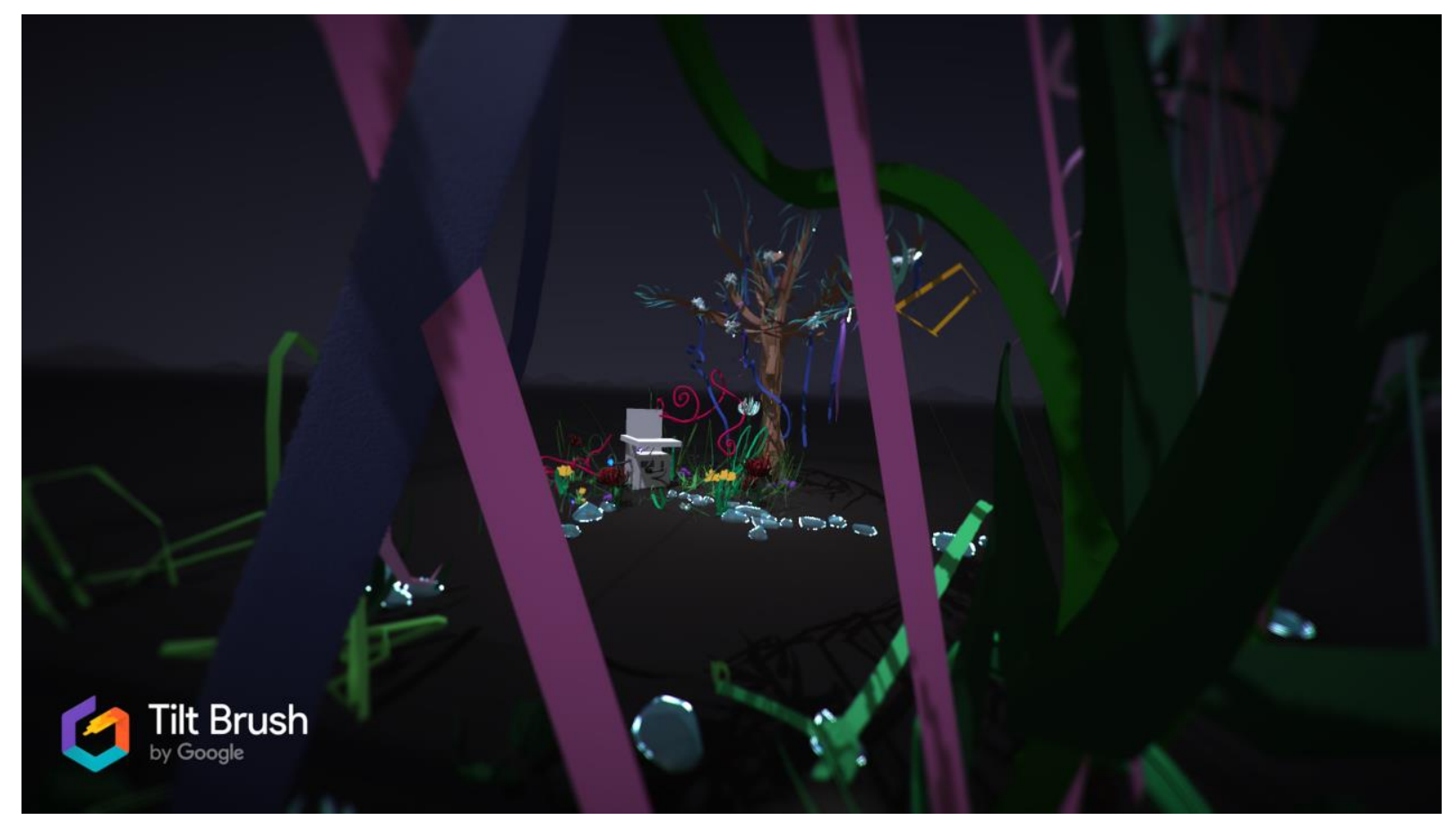

Note. This screenshot of Spacial Entrances (Orasi, Sameshima \& De Sommer-Dennis, 2020) reflects only one of the many possible perspectives from which to view in immersive VR. Link to full video: https://youtu.be/Q_We6RL6Zqo 


\section{Boundaries and Groundings}

As previously described, we see the virtual creative landscape as a curricular ma space, a burgeoning space where beginnings and becomings emanate (see Sameshima et al., 2019b). We liken the VR environment to the ma space where, within, there are no predetermined boundaries or structures to navigate, to be pushed forward into, or frameworks to influence a path dependency. The absence of expected ends or walls, inherently situates the learner in a world of self-determinacy. One cannot see the end, determine a right or better path, or rely on pathways of others. This gives the learner the ability to step forward into possibility, to create freely, and to be fully present with the agentic self. VR defies boundaries of both space and time (Lee et al., 2021).

Making in VR also reminds us of potentiality (Barad, 2007), the freedom from disappointment and lost hope that emerge from an over-reliance on pre-existing structures, boundaries and expectations, and provides a referent for the limitless potential of one's own creativity. The act of art-making in this space fosters learning and growth through creative autonomy, and invites us to revisit Piaget's (1997) theory of cognitive development. Piaget posited that at the most basic level, all species organize and adapt as part of their explorations, learnings and integration with the broader structure systems of the world. While he called this process "equilibration," developing literacies to communicate creativity in virtual reality disrupts this process by removing these structures and patterns of organization and presses the learner toward greater creative empowerment and autonomy, and thus, enables the building of more authentic knowledge structures. This finding is consistent with the Immersive Learning Research Network's State of XR Report which suggests that VR presents the opportunity for "empowering learners as creative designers and makers" (Lee, 2021, p. 27).

When entering a VR space, the first action is to confirm the ground. The user is directed to use one of the hand controllers to touch the floor. This motion calibrates the user's position. Despite the vast ability to create in the VR space, importantly the user needs to have a base, a ground from which to start creating. Groundedness or having a sense-of-place impacts identity, community and pedagogy (Sameshima \& Knowles, 2008; Wiles, 2008). The ground provides safety and enables an exploration based on that knowing. Another space of metaphorical ground can also be found in the "Home" environment button. This is the Oculus virtual home the user starts in. The built-in home environments of Classic Home and Winter Lodge are opulent homes users become accustomed to feeling as their base. It is from "home" that the user navigates to various activities. Blackie (2018) writes, we are "inextricably enmeshed in the world around us, it is hardly surprising that the nature of our relationship with our places is critical to our ideas about who we are and what might be possible for us to become" (p. 197). Blackie's words aptly describe how identity construction and environment are interrelated and further reiterates Freire's (1979) notion that "the more rooted I am in my location, the more I extend myself to other places so as to become a citizen of the world" (p. 39). Ground in the VR space is a stable, consistent space that is critical for supporting risk-taking and exploration.

\section{Creative Literacy and Expression}

Making in virtual reality extends what has come to be known as creative literacy by changing how and what can be said, and what it means to be able to read creativity. As a fully haptic immersive 360 experience, when connected to the headset, one can see, hear and feel the scrape of the paintbrush on the virtual canvas, despite its ontological absence. As a seemingly impossible projection, it allows for the maker to live inside a concept or an idea, to create and inhabit paracosms ${ }^{3}$ (Bronson \& Merryman, 2010) and to tinker and play within these by adding to, manipulating, and changing orientations in search of understanding.

Analogous to a foreign language, in VR, there are facets of creativity that are untranslatable into this paper and even to the MP4 video we created. These uniquely nuanced meanings can only be fully understood and appreciated by those who speak the same language or have the tools to receive and decode that message form. Even then, all modalities of communication are incomplete ${ }^{4}$. When one communicates, there is always loss because the capacity of language and of various literacies on their own are wanting. In the vein of Bowie's (2006) poststructuralist assertion that music is a language, creating in virtual reality exemplifies how all singular forms of text can never fully inform understandings of the world, nor support 
our ability to communicate. Creativity and expressive practices can therefore be seen as a translanguaging ${ }^{5}$ or, put another way, the cultivating of creativity while also developing the capacity to read meaning and the forms that convey it (Eisner, 2017, p. 51). As creative languages use different tools and systems to "write," they are not only opportunities for change in education through the decolonization of language learning ideologies, but also sites for leveraging the capacity of multiple languages and multilingualism in ways that deepen learner comprehension and engagement (Vogel \& Garcia, 2017).

VR is a space where desire can be materialized and communicated. Sameshima and Leggo (2010) describe the deep interrelation between desire and learning, pointing out that "creative works . . . are renderings of research, reflections of desire" (p. 70). They quote Sartre (1965) who describes desire as "consciousness making itself body" (p. 389) and Butler (1987) describing Hegel's notion of desire as embodied identity:

For Hegel, labor is 'inhibited desire', and recognition becomes the more sophisticated form of reflection that promises to satisfy desire" (p. 43). Butler (1987) contends that desire must become expressed through labor, for desire must give shape or form to the natural world in order to find itself reflected there. Giving form is thus the external determination of desire. (Sameshima \& Leggo, 2010, p. 57)

VR offers new possibilities to support the deep human desire to express the self and to communicate expressions of the self in order to be heard and seen, for the self to be known. Derrida (1978) writes of his wish to use his blood as ink, to "take ink before filtering the inscribable" (p. 12) as a way to align the translation of the rendered expression as fulsome to the inner knowing as possible. While constructing an environment around oneself in VR, the rendered creation is not outside of the self, but rather, conveys the self in the rendering. Creative literacy involves knowing how to use language as a tool to conveyance. Derrida, in an interview with Nikhil Padgaonkar (1979) explains, "when you inherit a language it does not mean you are totally in it, you are passively programmed by it. To inherit means to be able to, of course, appropriate this language, to transform it, to select something" (p. 2). He goes on to explain that language "calls for interpretations, selections, reactions, response and responsibility" (p. 2). Derrida confirms, "I would even say that in order to make something new happen, you have to inherit, you have to be inside the language, inside the tradition. You would not be able to transform or displace anything without in some way being inside the tradition, without understanding the language" (p. 2). By this, we interpret Derrida as advising that in order to develop new literacies of making and communicating, one has to first be immersed and proficient with the skill. This connoisseurship of creative literacy is not accessible to most people. Another pathway to being inside the literacy is to express experience from within. Falbel (1993) provides a clear explanation from educational theorist John Holt in an interview. Holt explains that the definition of education is "living" -- it is a process of becoming "informed, intelligent, curious, competent, skillful, aware of our interaction with the world around us" (pp. 13-14).

\section{Gaze and Pedagogy}

Reflecting on the reliance on web conferencing technologies during the pandemic has also enabled us to consider the relationship between control, power, communication and view in the classroom, and how the permission to view is shifted in the virtual landscape. In Zoom, the self controls what the other seesthe self sees itself, adjusts itself and even selects its visibility. The focus of the other's gaze is directed. In VR, the controller (the person wearing the headset) controls what the others viewing the casted screen are able to see. This constructed viewing frame forces the viewer to see from the controller's perspective. Without also being in the immersive space, a viewer only sees a picture, a $2 \mathrm{D}$ representation of what the controller wants the viewers to see.

Potska (1995) explains additional difficulties with "view" emanating from using such two-dimensional forms of visual communication in the classroom. Even with the use of graphs, pictures, diagrams, and movies, the impediments to view caused by the use of two-dimensional renderings of content that is ultimately experienced in 3D, can be sources of confusion and conflicting interpretations among learners 
(Potska, 1995). In VR however, interaction with content is replaced by immersion. As educational researchers aligned with constructivist epistemologies, we recognize that understandings are always incomplete: however, VR allows one to view allocentrically (Potska, 1995), which as we experienced, is the view from within the picture, from within another perspective. As an educational aspiration for knowledge construction and exchange, this is revolutionary. The teacher can see what the student sees.

In this interplay, walking in another's shoes creates space for empathy, love and close relation fueled by learning desire (Sameshima \& Leggo, 2010), and, as we experienced, celebration. Celebratory spaces of learning have the capacity of creating flow spaces (Csikszentmihalyi, 2004), constructed means of creating synthetic pure moods. "Ceremonies and celebrations are not just minor matters; rather, they prove the Heideggerian thesis that the primary unlocking of the world is found fundamentally only by way of pure moods" (Bollnow, 1989, p. 64). When in this place, one can wander with ease, leaving the heavy world behind. This place allows for unlimited learning and revelation. Bollnow writes: "a typical feature of festive celebration is extravagance and boisterousness. People feel themselves freed from and lifted above the limiting structures of everyday life (p. 72)" (Sameshima, 2007, p. 67). The celebratory space of collaborative creation is also a potluck pedagogy - a space where learners convene in a festive, welcoming space, each bringing an offering to the table, partaking voluntarily (Sameshima \& Sinner, 2009). Selfagency and self-determinacy by controlling one's own learning, engagement, and view is made possible within VR.

\section{FUTURE POSSIBILITIES THROUGH VR}

Generating data for analysis in VR, such as we have, provokes new possibilities for research frameworks. Profoundly, virtual reality enables a view of data or construction of analyses processes that place the researcher within the data exploration. While the Parallaxic Praxis model as shown in Figure 1 recognizes data viewed from multiple perspectives, the researchers are always situated outside the data. Conversely, when collaboratively creating in VR, each researcher is capable of viewing the constructed artworks within the space from all perspectives. VR presents a steeped space to indwell heuristically ${ }^{6}$ (see Djuraskovic \& Arthur, 2010; Moustakas, 1990) with data. The perceptual experience of creating in VR enhanced our knowledge of the phenomenon of presence and immersion and introduced an opportunity for a new inheritance of creative language with which to transform, interpret and respond (Derrida, 1997). VR explicates Freire's words, "a new reading of my world requires a new language - that of possibility, open to hope" (1997, p. 77). By that, we mean that research is not merely describing what is, in ethnographic, life history, or biographic research, but rather, a generative meaning-making, a material creative synthesis that drives forward a heuristic process (Moustakas, 1990).

\section{FIGURE 3}

\section{PARALLAXIC PRAXIS’ DYNAMIC FIELDS IN VIRTUAL REALITY}

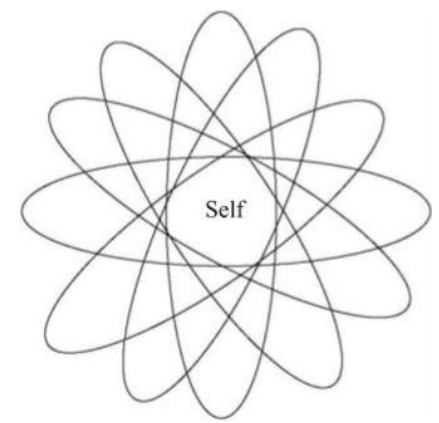

Note. Unlike in FIGURE 1, in virtual reality the researcher is situated within the data, able to shift and see data as well as interpretations from all perspectives. 
Receptivity and openness unfold possibilities for learning (Sameshima, 2008). In VR, the world can be experienced as a "stream of kinesthesis, cutaneous and visceral sensation, defining ... [the] body's space and extension and yielding information about position, balance, state of tension, desire, and mood" (Leder, 1990, p. 23). This receptive openness "is akin to Leder's notion of aesthetic absorption which is based on phenomenologist Maurice Merleau-Ponty's (1968) 'chiasm' which is experiencing the world as 'flesh'-a meshing of subject and object, self and body, and body and world" (Sameshima, 2008, p. 24). This immersive space expounds the necessity for risk, or moving the self into an unknown space, as an essential element of the ability to read creatively. VR expands the literacy of creativity and presents new pedagogies for thinking, making, analyzing data, and generating meaning.

This research acknowledges that there is much more to discover as digital classroom technologies and immersive VR become increasingly prevalent in mainstream society and in the lives of students and teachers. Despite its early difficulties, VR (and other immersive technology) is poised to fundamentally change education and student interactions with digital technologies (Lee et al., 2021). Ideas of ontological stability will be challenged in profound new ways as the connections between space, learning and creativity are fundamentally altered and the "opportunity to more directly integrate human experience into formal and informal education and workforce training" (Lee et al., 2021, p. 15).

The VR space is rich with important symbolic messages and social information for the enhancement of educational practice and multimodal research and research-creation projects (Loveless, 2019). Creating in this space highlights the possibilities to enhance the democratization of contemporary educational spaces, holistic communication, and draws important pedagogical attention to boundaries, ground, embodied communication, translation and creativity as literacies. VR platforms such as Google Tilt Brush challenge the ways personal creativity is influenced by spatial arrangements and "our interpretations of them and orientations toward them" (Hitchcock \& Hughes, 1989, p. 172). Creating in virtual reality evolves the educational landscape into one that can be inhabited and co-created, removing boundaries of colonizing structures and languages. As a multimodal way of engaging with data and each other, this space allows for student-teacher "becomings-with" (Haraway, 2016) and the evolution of new creative and pedagogical languages that are entangled, reciprocal and reparative (Sameshima \& Slingerland, 2015), especially poignant in pandemic times.

As the world continues to grapple with an ongoing global pandemic, and virtual reality technology continues to expand into and beyond mobile learning contexts, other invisible literacies (Barton et al., 2018), such as a vision of socially accountable futures literacy ${ }^{7}$ (Miller, 2018) will only exist in a society that embraces the value of creative literacy and the pedagogical space(s) where it is permitted to thrive. In the words of Eisner (2002), "what we look for and what we know how to say is constrained by the tools we know how to use" (p. 36). If indeed, the choice of the tool is what enables different possibilities for answers, virtual reality is one whereby moving beyond engaging with the present, educators can co-envision, coinhabit, co-create a future life world (Sameshima et al., 2019).

\section{ACKNOWLEDGEMENTS}

We sincerely thank Emilee De Sommer Dennis for her significant contributions in the collaboration of the video Spacial Entrances which laid the ground for theorizing this paper. We also want to acknowledge earlier work by Matthew O'Reilly and Pauline Sameshima from their presentation on the ceramic transmediations, "The Teacher Figures" (O'Reilly) and "Silent Belles" (Sameshima), presented in a research team meeting at the University of British Columbia in December 2017 for the Social Sciences and Humanities Research Council funded grant titled: Reconceptualizing Teachers' Roles for Canada's Creative Economy. Finally, we sincerely thank Valerie Gibbons and Garth Galvin at Lakehead University Library for their gracious support and assistance with the use of the 3D printing equipment and Google Tilt Brush platform. 


\section{ENDNOTES}

1. The Catechization Process is a reflexive means to systematically analyze the renderings in a dialogic environment and is an integral part of the Parallaxic Praxis Model. For more information, please see: https://www.solspire.com/research-model.html

2. "Reconceptualizing Teachers' Roles for Canada's Creative Economy" is a study funded by the Social Sciences and Humanities Research Council (2017-2021). In December 2017, this team met to discuss their particular site data and to participate in a Catechization Process. At that meeting, the team used artworks made by Matthew O'Reilly and Pauline Sameshima (see https://www.solspire.com/teacher-creativity.html) as creative propulsion tools.

3. A paracosm is a complex imaginative world created and used for play by children (Bronson \& Merryman, 2010).

4. Quality of communication might be viewed according to granulation where fine-grained communications describe more details than coarse-grained communications. Interestingly, in arts-based research, Eisner's (2017) connoisseurship refers to the attention given to fine nuances of detail. This possibility of accessing fine-grained detail is inherently accessible in VR spaces' capacity to zoom in and enlarge. Access to connoisseurship is created via pixelation capacity.

5. Cen Williams (1980) defines translanguaging as the process that bilingual individuals use to communicate as fully as possible by using one or more languages integratively instead of communicating exclusively in a single language. Translanguaging is when an individual uses all their linguistic and cognitive resources to communicate (Vogel \& Garcia, 2017).

6. Moustakas (1990) describes Heuristic Methodology as consisting of six phases: Initial Engagement, Immersion, Incubation, Illumination, Explication and Creative Synthesis.

7. According to UNESCO (n.d.), futures literacy is the "innate human ability to imagine the future" (online).

\section{REFERENCES}

Babich, N. (2019, September 19). How VR education will change how we learn and teach. AdobeXD. Retrieved from https://xd.adobe.com/ideas/principles/emerging-technology/virtual-reality-willchange-learn-teach/

Barad, K.M. (2007). Meeting the universe halfway: Quantum physics and the entanglement of matter and meaning. Duke University Press.

Barton, G., Lemieux, A., \& Chabanne, J. (2018, August 6). Invisible literacies are the literacies for the future. What are they? Why is teaching them vital? Australian Association for Research in Education. Retrieved from https://www.aare.edu.au/blog/?p=3097

Bengfort, J. (2020, February 17). Virtual reality advances bring new possibilities to higher education. EdTech. Virtual Reality Advances Bring New Possibilities to Higher Education. Retrieved from https://edtechmagazine.com > higher > article > 2020/02

Bowie, A. (2006). Aesthetics and subjectivity (2nd ed.). Manchester University Press.

Butler, J. (1987). Subjects of desire: Reflections in twentieth-century France. Columbia University Press.

Canada Council for the Arts. (2020, November 26). Participants announced for the UK-Canadian Co Production Programme for immersive Storytelling. Retrieved fromhttps://canadacouncil.ca /press/2020/11/inaugural-cohort-announced-in-uk-canada-immersive-exchange

Cochrane, T. (2016). Mobile VR in education: From the fringe to the mainstream. International Journal of Mobile and Blended Learning (IJMBL), 8(4), 44-60. doi: 10.4018/IJMBL.2016100104

Cole, A.L., \& Knowles, J.G. (2001b). Qualities of inquiry. In L. Neilsen, A. Cole, \& J.G. Knowles (Eds.), The art of writing inquiry (Vol. 1. Arts-informed Research Series, pp. 211-219). Backalong Books.

Cole, D., \& Masny, D. (2009). Multiple literacies theory: A Deluzian perspective. Brill/Sense.

Csikszentmihalyi, M. (2004). Flow, the secret to happiness. TED2004. Retrieved from https://www.ted.com/talks/mihaly_csikszentmihalyi_flow_the_secret_to_happiness?language=en

Derrida, J. (1978). Writing and difference (A. Bass, Trans.). Chicago University Press. 
Djuraskovic, I., \& Arthur, N. (2010). Heuristic inquiry: A personal journey of acculturation and identity reconstruction. The Qualitative Report, 15(6), 1569-1593. http://10.46743/2160-3715/2010.1361

Eisner, E. (2002). Arts and the creation of mind. Yale University Press.

Eisner, E. (2017). The enlightened eye: Qualitative inquiry and the enhancement of educational practice. Teachers College Press Columbia.

Eisner, E., \& Barone, T. (2012). Arts Based Research. Sage.

Falbel, A. (1993, May/June). Learning? Yes of course. Education? No thanks. Growing Without Schooling, 92, 13-14.

Gillis, A., \& Krull, L.M. (2020). COVID-19 Remote learning transition in spring 2020: Class structures, student perceptions, and inequality in College Courses. Teaching Sociology, 48(4), 283-299. https://doi.org/10.1177/0092055X20954263

Ginsberg, S. (2012). 3D printing and creative literacy: Why maker culture benefits libraries. In K. Fontichiaro (Ed.), Everything you wanted to know about information literacy but were afraid to Google (pp. 89-92). Retrieved from http://www.observatorioabaco.es/biblioteca/docs 1372_UML_GOOGLE_2012.pdf\#page=89

Glenberg-Johnson, M. (2018). Immersive VR and education: Embodied design principles that include gestures and hand controls. Frontiers in Robotics and AI, 5(81). http://doi.10.3389/frobt.2018.00081

Gronstedt Group. (2020, January 28). Immersive tech that will change learning in 2020 and beyond [Webinar]. Retrieved from https://www.gronstedtgroup.com/webcasts

Haraway, D. (2016). Staying with the trouble: Making kin in the Chthulucene. Duke University Press. Hasebe-Ludt, E. (2019). Of lanterns and liminal moments: Living curriculum in the key of Ted Tetsuo Aoki. In P. Sameshima, B. White, \& A. Sinner (Eds.), Ma: Materiality in teaching and Learning (pp. 3-16). Peter Lang.

Hayes, M.T., Sameshima, P., \& Watson, F. (2014). Imagination as method. International Journal of Qualitative Methods, 14(1), 36-52.

Hitchcock, G., \& Hughes, D. (1989). Research and the teacher. Routledge.

Hughes, C., \& Moshell, J. (1997). Shared virtual worlds for education: The Explore Net Experiment. Multimedia Systems, 5, 145-154. https://doi.org/10.1007/s005300050050

James, K. (2019). Spring. In P. Sameshima, B. White, \& A. Sinner (Eds.), Ma: Materiality in teaching and Learning (pp. 221-232). Peter Lang.

Larson, N., Mortensen, J.K., \& Miller, R. (2020, February 11). What is 'Futures Literacy' and why is it important: On overcoming blind resistance to change and poverty of the imagination. Medium. Retrieved from https://medium.com/copenhagen-institute-for-futures-studies/what-is-futuresliteracy-and-why-is-it-important-a27f24b983d8\#: :text=Futures\%20literacy\%20enables\% 20us\%20to,and $\% 20$ the $\% 20$ choices $\% 20$ we\%20make

Leder, D. (1990). The absent body. Chicago University Press.

Lee, M.J.W., Georgieva, M., Alexander, B., Craig, E., \& Richter, J. (2021). State of XR \& Immersive Learning Outlook Report 2021. Immersive Learning Research Network. Retrieved from https://immersivelrn.org/stateofxr_2021/

Leggo, C. (2019). Ma: Lingering in the alphabet. In P. Sameshima, B. White, \& A. Sinner (Eds.), Ma: Materiality in teaching and Learning (pp. 205-220). Peter Lang.

Lewington, J. (2020, February 4). Augmented and virtual reality are helping colleges up their tech game: It's not just for finding Pokemon anymore. Macleans. Retrieved fromhttps://www.macleans.ca /education/college/augmented-virtual-reality-colleges-technology-learning/

Li, T. (2018, November 13). Lenovo introduces virtual reality classroom to Canadian education. ITBusiness. Retrieved from https://www.itbusiness.ca/news/lenovo-introduces-virtual-realityclassroom-to-canadian-education/106718

Loveless, N. (2019). How to make art at the end of the world: A manifesto for research-creation. Duke University Press. 
Masny, D. (2009). Literacies as becoming: A child's conception of writing systems. In D. Cole \& D. Masny (Eds.), Multiple literacies theory: A Deluzian perspective (pp. 25-42). Sense.

Moustakas, C.E. (1990). Heuristic research: Design, methodology, and applications. Sage.

Orasi, T., \& Sameshima, P. (2020, March 3). Matters of meaning in education: Raising acuity [3D Printed Interactive Diorama from SSHRC-funded project: Reconceptualizing Teachers' Roles for Canada's Creative Economy]. Exhibition. Research and Innovation Week. The SPACE Gallery, CASES Building Lakehead University, Thunder Bay, ON.

Orasi, T., Sameshima, P., \& De Sommer-Dennis, E. (2020, March 3-2021, March). Spacial Entrances [Video from SSHRC-funded project: Reconceptualizing Teachers' Roles for Canada's Creative Economy]. Exhibition: The SPACE, CASES Building, Lakehead University.

Padgaonkar, N. (1997, March 17). An interview with Jacques Derrida. Retrieved from http://mural.uv.es/mibosa/DerridaInterview2.htm

Pantelidis, V. (1993). Virtual reality in the classroom. Educational Technology, 33(4), 23-27. Retrieved from http://www.jstor.org/stable/44428033

Pantelidis, V. (2009). Reasons to use virtual reality in education and training courses and a model to determine when to use virtual reality. Themes in Science and Technology Education, 2, 59-70. Retrieved from https://www.researchgate.net/publication/268002587_Reasons_to_Use_Virtual_ Reality_in_Education_and_Training_Courses_and_a_Model_to_Determine_When_to_Use_Virtu al_Reality

Piaget, J. (1997). The language and thought of a child (3rd Ed.). Routledge.

Psious. (2020). Clinical guide. Retrieved from https://psious.com/

Psotka, J. (1995). Immersive training systems: Virtual reality and education and training. Instructional Science, 23, 405-431. https://doi.org/10.1007/BF00896880

Sameshima, P. (2007). Seeing Red-a pedagogy of parallax: An epistolary bildungsroman on artful scholarly inquiry. Cambria Press.

Sameshima, P. (2008). Letters to a new teacher: A curriculum of embodied aesthetic awareness. Teacher Education Quarterly, 35(2), 29-44. Retrieved from http://www.jstor.org/stable/23479222

Sameshima, P. (2019). Ma, I'm thinking about nothing. In P. Sameshima, B. White, \& A. Sinner (Eds.), Ma: Materiality in teaching and Learning (pp. 3-16). Peter Lang.

Sameshima, P. (2020, November 29). Why parallaxic praxis and arts integrated studies can make a better future. Royal Society of Canada Cafe: New member lightning talks. Celebration of Excellence and Engagement. University of Toronto. Hosted online. Retrieved from https://www.youtube.com/watch? $\mathrm{v}=5 \mathrm{mpM} 374 \mathrm{~F} 6 Y \mathrm{~s} \& \mathrm{t}=3 \mathrm{~s}$

Sameshima, P., \& Knowles, J.G. (2008). Into artfulness: Being grounded but unbounded. In J.G. Knowles, A. Cole, L. Neilsen, \& S. Promislow (Eds.), Creating scholartistry: Imagining the artsinformed thesis or dissertation (Vol. 4, Arts-Informed Inquiry Series, pp. 108-121). Backalong Books.

Sameshima, P., \& Leggo, C. (2010). The poet's corpus in love: Passionate pedagogy. Journal of Curriculum Theorizing, 26(1), 65-81. Retrieved fromttps://journal.jctonline.org/index.php/jct/article/view/146/62

Sameshima, P., \& Sinner, A. (2009). Awakening To soma heliakon: Encountering teacher-researcherlearning in the $21^{\text {st }}$ Century. Canadian Journal of Education, 32(2), 271-284. Retrieved from https://journals.sfu.ca/cje/index.php/cje-rce/article/view/3042

Sameshima, P., \& Slingerland, D. (2015, August). Reparative pedagogy: Empathic aesthetic learning. Canadian Review of Art Education, 42(1), 1-21.

Sameshima, P., Maarhuis, P., \& Wiebe, S. (2019). Parallaxic praxis: Multimodal interdisciplinary pedagogical research design. Vernon Press.

Sameshima, P., White, B., \& Sinner, A. (2019b). Ma: Materiality in teaching and learning. Peter Lang.

Sameshima, P., Wiebe, S., \& Hayes, M. (2019c). Imagination: The generation of possibility. In B. Andrews (Ed.), Perspectives on arts education research in Canada, Volume 1: Surveying the landscape (pp. 19-35). Brill Sense. 
Sartre, J. P. (1956). Being and nothingness: An essay on phenomenological ontology. (Hazel. E. Barnes, Trans.). Philosophical Library. (Original work published 1943)

Sesqui. (2017-2021, January 30). What is sesqui. Retrieved from http://sesqui.ca/en/about/

Thompson, D.S., Thompson, A.P., \& McConnell, K. (2020). Nursing students' engagement and experiences with virtual reality in an undergraduate bioscience course. International Journal of Nursing Scholarship, 17(1), 20190081. https://doi.org/10.1515/ijnes-2019-0081

Traxler, J., \& Wishart, J.M. (2011). Making mobile learning work: Case studies of practice. (Discussion Papers in Education). ESCalate at the University of Bristol, HEA Subject Centre for Education. Retrieved from https://core.ac.uk/download/pdf/29026891.pdf

UNESCO. (n.d.). Futures literacy. Retrieved from https://en.unesco.org/themes/futures-literacy

Varjo. (2021). A guide to the transformative power of virtual reality and mixed reality (v.7). Retrieved from https://varjo.com/e-book/guide-to-the-transformative-power-of-virtual-reality-and-mixedreality/

Vogel, S., \& García, O. (2017, December 19). Translanguaging. Oxford Research Encyclopedia of Education. Retrieved

fromhttps://oxfordre.com/education/view/10.1093/acrefore/9780190264093.001.0001/acrefore9780190264093-e-181 